\title{
Evolution of Shrinkage with Carbon Equivalent and Inoculation in Ductile Cast Irons
}

\author{
Anna Regordosa ${ }^{1, a}$, Nuria Llorca-Isern ${ }^{1, b}$, Jon Sertucha ${ }^{2, c *}$ \\ and Jacques Lacaze ${ }^{3, d}$
}

${ }^{1}$ Departament de Ciència de Materials i Química Física, Facultat de Química, Universitat de Barcelona, E-08028 Barcelona, Spain

${ }^{2}$ Investigación y Desarrollo de Procesos Metalúrgicos, IK4-Azterlan, Aliendalde auzunea 6, E-48200 Durango (Bizkaia), Spain

${ }^{3}$ CIRIMAT, Université de Toulouse, ENSIACET, F-31030 Toulouse, France

aaregorro7@alumnes.ub.edu, bnullorca@ub.edu, cjsertucha@azterlan.es, jacques.lacaze@ensiacet.fr

Keywords: nodular cast iron, shrinkage, inoculation, carbon equivalent

\begin{abstract}
Studying how shrinkage porosity changes size when varying the composition of ductile irons is still of interest for manufacturing sound cast parts and defining optimised processing conditions. Usual changes in carbon and silicon contents strongly affect shrinkage, so that a detailed analysis of the effect of alloy composition and of inoculation level on porosity was carried out in the present study. Two test castings have been used to evaluate the extent of porosity formed using different compositions and inoculation levels. It has been observed that increasing carbon content from hypoeutectic to near-eutectic compositions reduces the amount of defects while a further increase of shrinkage porosity is detected for hypereutectic compositions. Thus, a minimum in shrinkage tendency exists for slightly hypereutectic compositions. Although inoculation decreases shrinkage, the relevance of this parameter varies as a function of carbon equivalent.
\end{abstract}

\section{Introduction}

Shrinkage porosity is one of the most common defects in ductile iron castings which can provoke severe scrap levels in foundry plants. For a given layout, it is also observed that shrinkage may vary according to casting conditions leading to results that depend on production batches. Among the processing variables which have shown an important influence on contraction defects, carbon equivalent $C_{\mathrm{eq}}$ of alloys [1-4] and inoculation process [2-4] appear as the most critical ones. Both parameters are strongly related to graphite expansion during solidification to compensate for the liquid to austenite contraction. It thus seems to be of high interest to study the relationship between shrinkage evolution and these two parameters using different casting sizes and geometries.

Casting layout and related feeders are first considered in foundry plants for decreasing shrinkage. However, use of oversized risers is being avoided in foundry practice for reduction in production costs. Thus, effective control of mass production processes must be increased and a deeper understanding of the processing conditions to manufacture sound castings becomes more decisive. In relation to this latter aspect, the positive effect of high carbon equivalent and inoculation to minimise shrinkage formation has been reported elsewhere [2-3, 5]. However, optimisation of these two parameters still requires a better knowledge of their effects on casting soundness.

The present work shows the evolution of shrinkage size and features in two layouts with different casting types and feeding behaviours. These systems have been used to produce castings with different $\mathrm{C}_{\text {eq }}$ values and inoculant additions. The first arrangement is composed of a massive casting which can be satisfactorily fed by the corresponding riser while the second one shows a comparatively small casting that contains a "hot spot" with strong difficulty to be fed. Special attention has been focused on shrinkage porosity found in risers (first layout) and the critical zones (second layout). 


\section{Experimental Details}

Casting series 1. In the first series, 11 inoculated alloys were cast in green sand moulds prepared with a high pressure automatic horizontal moulding line as reported by Gutiérrez et al. [3] where full experimental details are included. Melts were $\mathrm{Mg}$-treated with a FeSiMg alloy (grain size 2-10 mm, 45.7 Si, 5.5 Mg, 2.42 Ca, 0.39 Al, 2.24 rare earth, wt.\%). Four casting-riser assemblies as schematically shown in Fig. 1-a were cast per mould. For this series, the riser modulus was calculated as 1.3, 1.0 and 0.9 times the critical modulus of the casting $(1.24 \mathrm{~cm})$. The weight of each assembly was in the range $13.6-16.2 \mathrm{~kg}$ for a casting weight of $11.9 \mathrm{~kg}$. In this series, the inoculation treatment was the same for all castings and was carried out by adding $0.18 \mathrm{wt} \%$ of a commercial inoculant (grain size 0.2-0.6 mm, 63.6 Si, 0.87 Al, $1.03 \mathrm{Ca}, 3.25 \mathrm{Mn}, 3.56 \mathrm{Zr}$, wt.\%). The composition ranges for the 11 alloys are listed in Table 1 where $\mathrm{C}$ refers to carbon content determined by combustion while $\mathrm{C}_{\mathrm{TA}}$ represents the carbon content obtained from cooling curves of tellurium-whitened melt samples. The range of carbon equivalent obtained for this first series is 4.28-4.41 wt.\% for carbon contents determined by combustion $\left(\mathrm{C}_{\mathrm{eq}}\right)$ and $4.23-4.43 \mathrm{wt} . \%$ for those obtained from thermal analysis $\left(\mathrm{C}_{\text {eqTA }}\right) . \mathrm{C}_{\mathrm{eq}}$ was calculated according to Castro et al. [6]. After casting, the assemblies were conditioned and tomography was used to evaluate the shrinkage size in the risers. On the whole, the 47 casting-riser assemblies cast with inoculated alloys [3] were considered.

Table 1. Composition ranges of alloys prepared in the first series (wt.\%), balance Fe.

\begin{tabular}{|c|c|c|c|c|c|}
\hline $\mathrm{C}$ & $\mathrm{C}_{\mathrm{TA}}$ & $\mathrm{Si}$ & $\mathrm{Mn}$ & $\mathrm{P}$ & $\mathrm{S}$ \\
\hline $3.57-3.72$ & $3.48-3.74$ & $2.17-2.38$ & $0.37-0.52$ & $0.013-0.027$ & $0.002-0.007$ \\
\hline $\mathrm{Ni}$ & $\mathrm{Cr}$ & $\mathrm{Cu}$ & $\mathrm{Sn}$ & $\mathrm{Ti}$ & $\mathrm{Mg}$ \\
\hline $0.017-0.022$ & $0.044-0.068$ & $0.51-0.92$ & $0.015-0.033$ & $0.010-0.024$ & $0.030-0.044$ \\
\hline
\end{tabular}
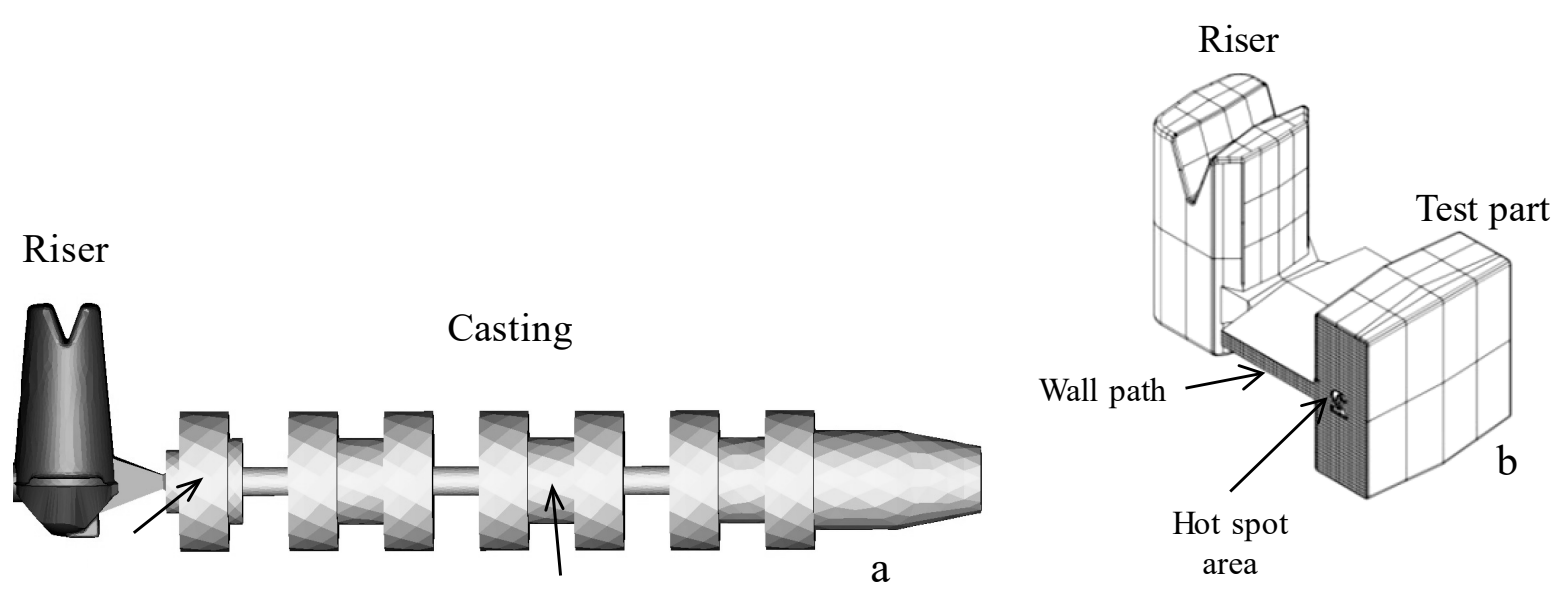

Figure 1. The two casting-riser layouts used in the present work.

Casting series 2. The second series of castings was carried out with the layout shown in Fig. 1-b. This layout was used to prepare green sand moulds by means of an automatic vertical moulding line located in the workshop of a foundry plant. Each mould contained one cavity for the present study in addition to castings for other purposes. The designed test part was composed of a massive zone connected to a riser by means of a horizontal thin-section wall path. Thus, effective feeding was not expected during an important part of the solidification period due to the thin-wall area and the highest risk of shrinkage was expected in the last solidifying zone. The weight of each test part and assembly was $2.3 \mathrm{~kg}$ and $4.6 \mathrm{~kg}$ respectively.

A total of 35 alloys were used in this second series which were cast to produce 112 test part-riser assemblies. Melts were treated with a FeSiMg alloy (45.4 Si, 3.0 Ca, 9.2 Mg, 2.9 rare earth, wt.\%) by means of the sandwich method. Post-inoculation was carried out by adding inoculant (grain size $0.2-0.7 \mathrm{~mm}, 70.5 \mathrm{Si}, 3.7 \mathrm{Al}, 1.03 \mathrm{Ca}$, wt.\%) at three different levels $(0.10,0.20$ or $0.30 \mathrm{wt} . \%$ of the 
casting weight). After cooling, the assemblies were removed from the moulds and properly cleaned. The test parts were then cut in half to reveal the internal porosity formed during solidification. The area of this porosity was finally measured using an image analysis software. Full experimental details about this second series have been reported elsewhere [4]. Composition ranges of cast alloys for all significant elements are shown in Table 2 where $\mathrm{C}$ refers to carbon content determined by combustion and the contribution of inoculation to silicon contents has been considered. The range of carbon equivalent obtained by combustion for this second series $\left(C_{\text {eq }}\right)$ is $4.05-4.63 \mathrm{wt} . \%$.

Table 2. Composition ranges of alloys prepared in the second series (wt.\%), balance Fe.

\begin{tabular}{|c|c|c|c|c|c|}
\hline $\mathrm{C}$ & $\mathrm{Si}$ & $\mathrm{Mn}$ & $\mathrm{P}$ & $\mathrm{S}$ & $\mathrm{Cr}$ \\
\hline $3.44-3.82$ & $2.04-2.94$ & $0.27-0.40$ & $0.019-0.032$ & $0.003-0.008$ & $0.039-0.065$ \\
\hline $\mathrm{Ni}$ & $\mathrm{Al}$ & $\mathrm{Cu}$ & $\mathrm{Sn}$ & $\mathrm{Ti}$ & $\mathrm{Mg}$ \\
\hline $0.023-0.043$ & $0.005-0.014$ & $0.07-0.45$ & $0.003-0.005$ & $0.015-0.026$ & $0.027-0.056$ \\
\hline
\end{tabular}

\section{Results}

Among the 11 alloys of the first series, four are hypoeutectic, three are nearly eutectic and the last four hypereutectic at different levels. In series 2, nine alloys are hypoeutectic, five nearly eutectic and 21 are hypereutectic. Fig. 2 compares the standard thermal analysis curves recorded from alloys with different $\mathrm{C}_{\mathrm{eq}}$ values used from series 1 (Fig. 2-a) and from series 2 (Fig. 2-b). Hypoeutectic alloys present a clear arrest at the austenite liquidus, at a temperature that decreases with increasing $\mathrm{C}_{\mathrm{eq}}$ from hypoeutectic to eutectic composition. For near eutectic and eutectic alloys, this arrest merges with the eutectic plateau. For hypereutectic alloys, a pre-eutectic reaction is evidenced at about $1160^{\circ} \mathrm{C}$ in the graphs of Fig. 2, which becomes stronger and stronger as $\mathrm{C}_{\mathrm{eq}}$ increases (as can be seen when comparing the curve for alloy 11 in Fig. 2-a with that for alloy 6 in Fig. 2-b). This pre-eutectic reaction sets up when primary graphite precipitates get surrounded by austenite [7].
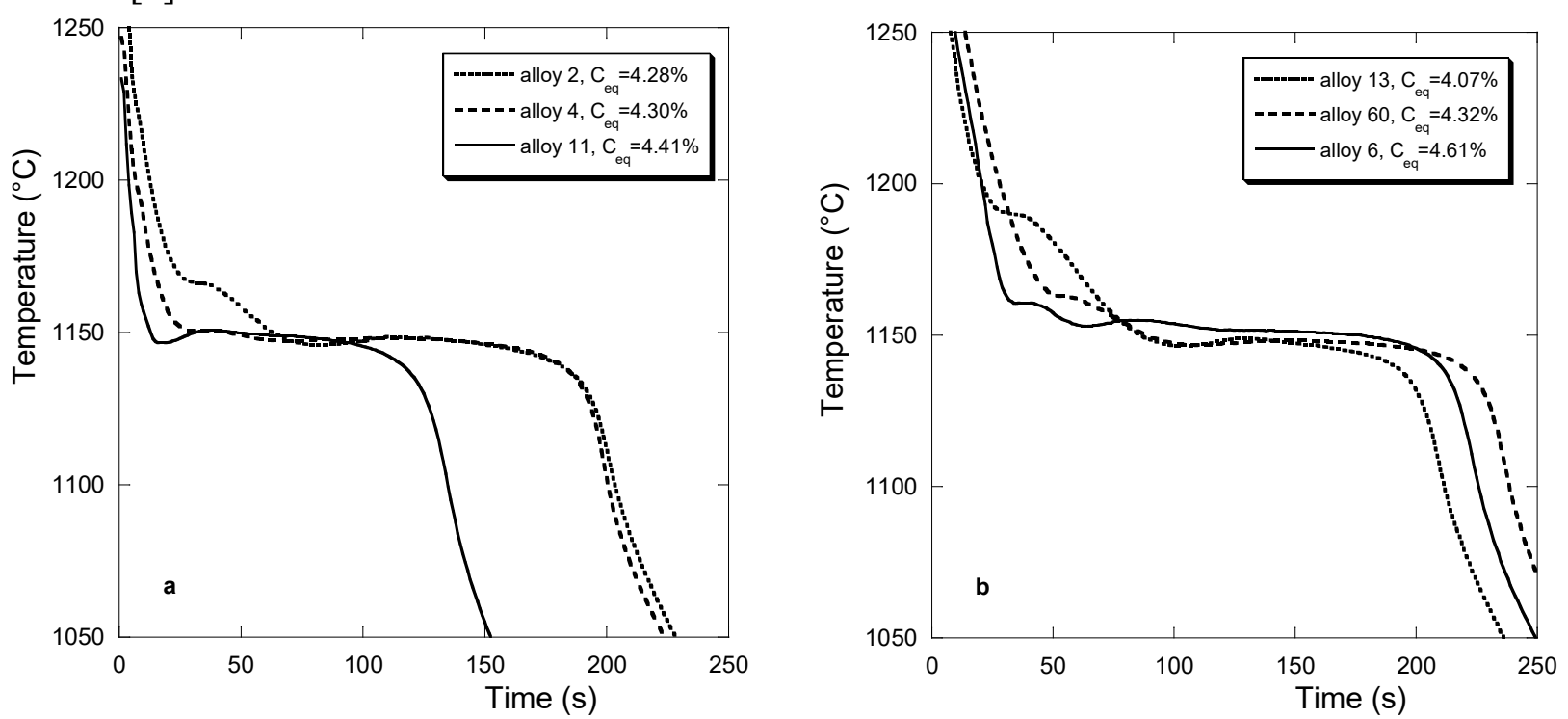

Figure 2. Cooling curves for alloys with different carbon equivalent from series 1 (a) and series 2 (b).

In the first series of castings, shrinkage was detected in all risers at various levels while only five castings were found to contain small porosity in the areas pointed with solid arrows in Fig. 1-a. The size of this porosity $\left(0.02-0.10 \mathrm{~cm}^{3}\right)$ was by far much lower than the shrinkage volume measured in risers as illustrated in Fig. 3-a. It is noticeable that these five castings showing small porosity were those manufactured with the two alloys with the lowest $\mathrm{C}_{\mathrm{TA}}$ values $(3.48-3.60 \mathrm{wt} . \%)$.

Among the 112 test parts from series 2, 43 were obtained without any detectable shrinkage porosity. In the remaining castings shrinkage was found at different levels depending on casting 
conditions and alloy composition. In all cases, shrinkage was located in the "hot spot" of the casting as illustrated with Fig. 3-b where it is also seen that small-size porosity is present alongside the shrinkage voids. Other examples will be presented later.
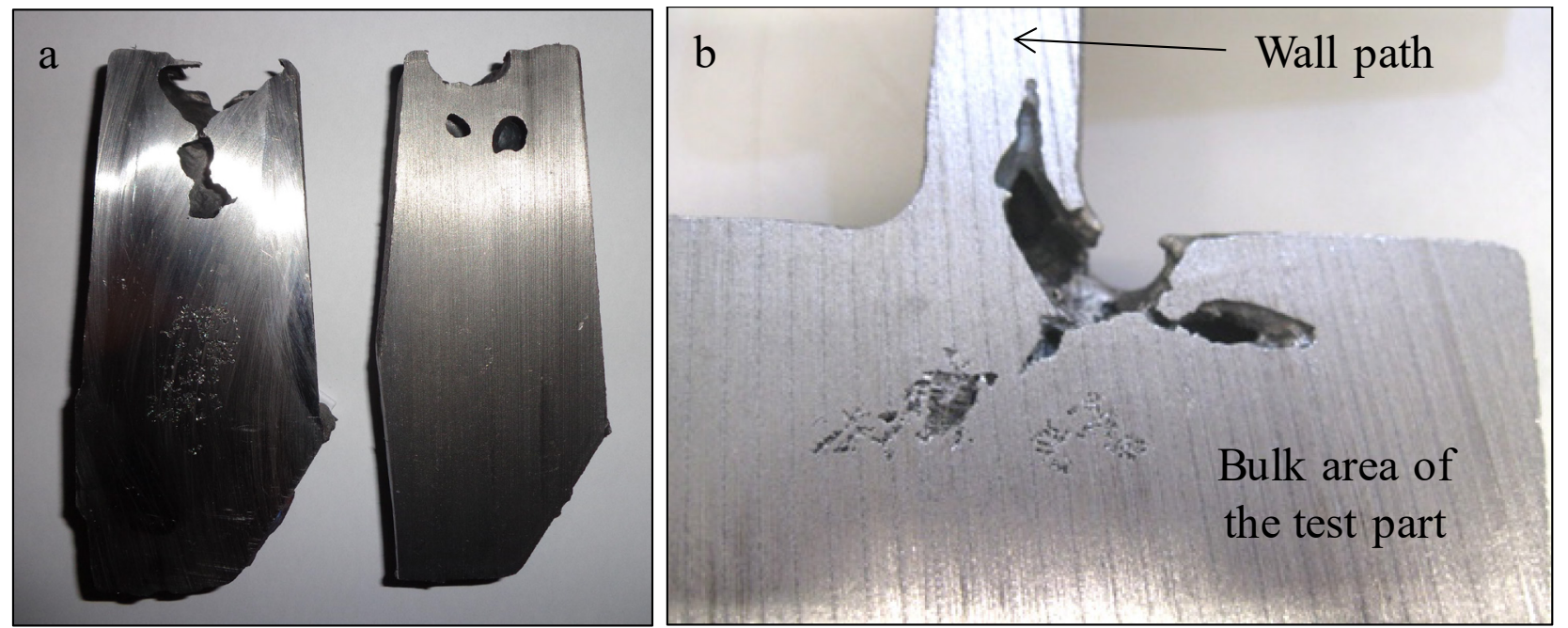

Figure 3. Shrinkage defects found at the top of two risers of $4.2 \mathrm{~kg}$ from series 1 (a) and in the hot spot area of a test part from series 2 (b).

The graphs in Fig. 4-a and Fig. 4-b show respectively the evolution with $\mathrm{C}_{\mathrm{eq}}$ of the shrinkage volume in risers $\left(\mathrm{V}_{\text {shr-riser }}\right)$ for casting series 1 and of the shrinkage area $\left(\mathrm{A}_{\text {shr-part }}\right)$ for the test parts of series 2. For the results of series 1 it was found that the use of $\mathrm{C}_{\mathrm{TA}}$ instead of the carbon content determined by combustion for calculating $\mathrm{C}_{\mathrm{eq}}$ gave much better correlation. $\mathrm{C}_{\mathrm{eqTA}}$ was thus used in this case. In both graphs, a minimum appears for near-eutectic compositions, more precisely for $\mathrm{C}_{\text {eqTA }}$ in between 4.39 and 4.42 wt.\% (Fig. 4-a) and $\mathrm{C}_{\text {eq }}$ in between 4.30 and 4.36 wt.\% (Fig. 4-b).
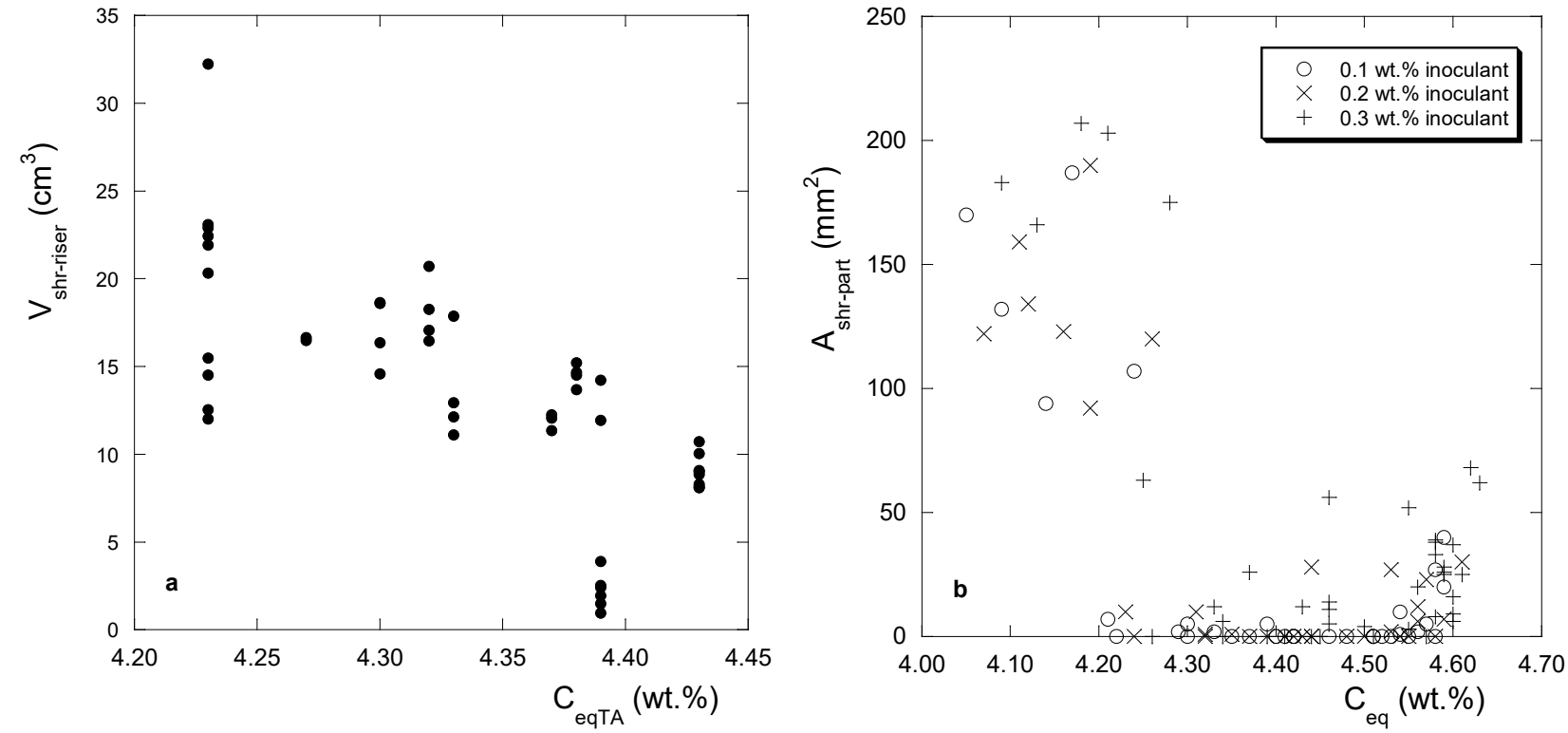

Figure 4. Evolution of $\mathrm{V}_{\text {shr-riser }}$ with $\mathrm{C}_{\text {eqTA }}$ for series 1 (a) and $\mathrm{A}_{\text {shr-part }}$ with $\mathrm{C}_{\text {eq }}$ for series 2 (b).

Fig. $4 \mathrm{~b}$ also shows the effect of the inoculation level on the evolution of $\mathrm{A}_{\text {shr-part }}$ with $\mathrm{C}_{\mathrm{eq}}$. In the whole range of $\mathrm{C}_{\mathrm{eq}}$ values investigated, it is observed that alloys with the highest inoculant addition present comparatively higher shrinkage than alloys with lower inoculation. It is worth stressing that hypereutectic alloys inoculated at $0.2 \mathrm{wt} \% \%$ show shrinkage as soon as $\mathrm{C}_{\mathrm{eq}}$ is higher than $4.44 \mathrm{wt} . \%$ while this value increases up to $4.54 \mathrm{wt} . \%$ for alloys inoculated at $0.1 \mathrm{wt} . \%$. 

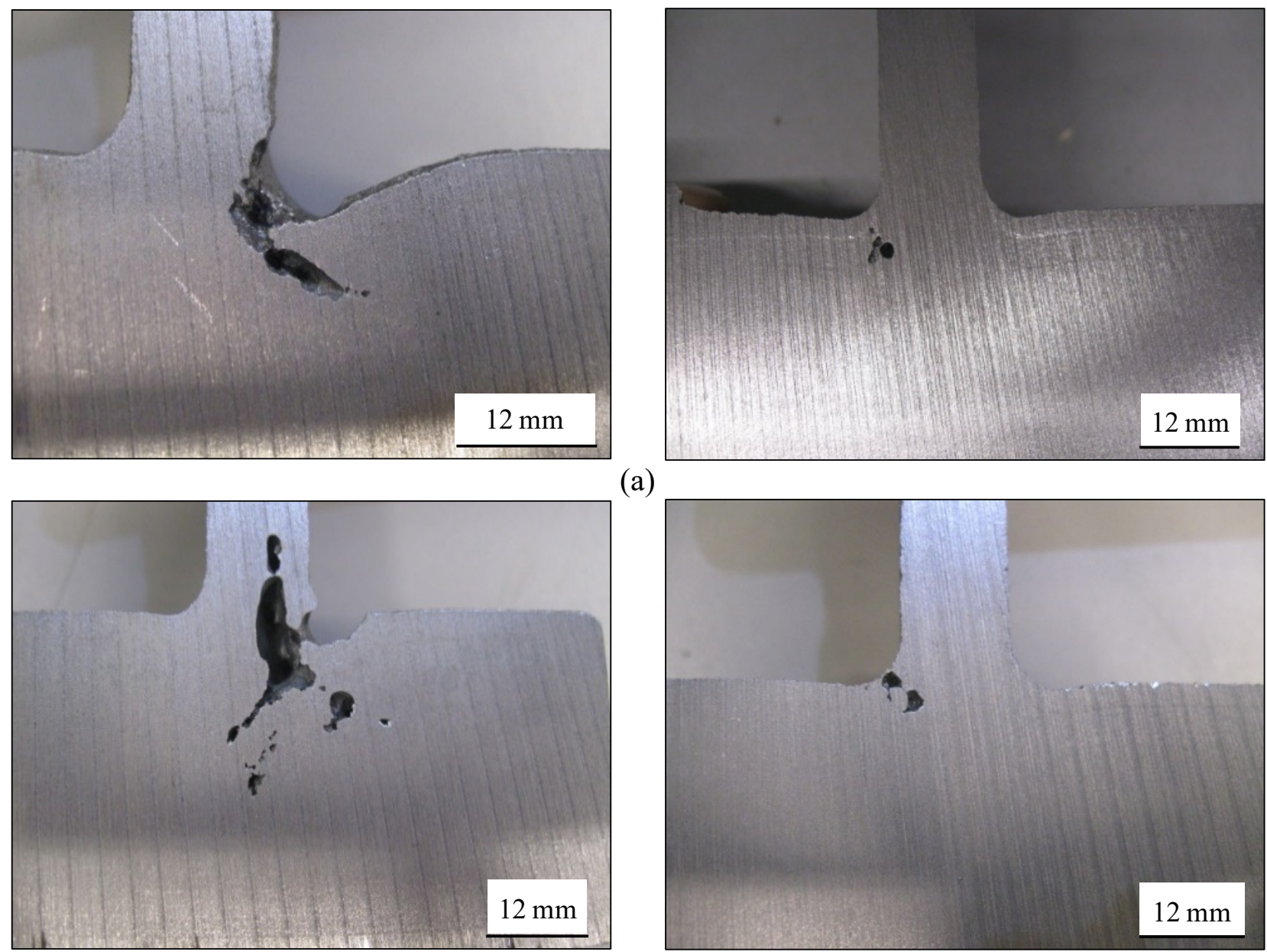

(a)

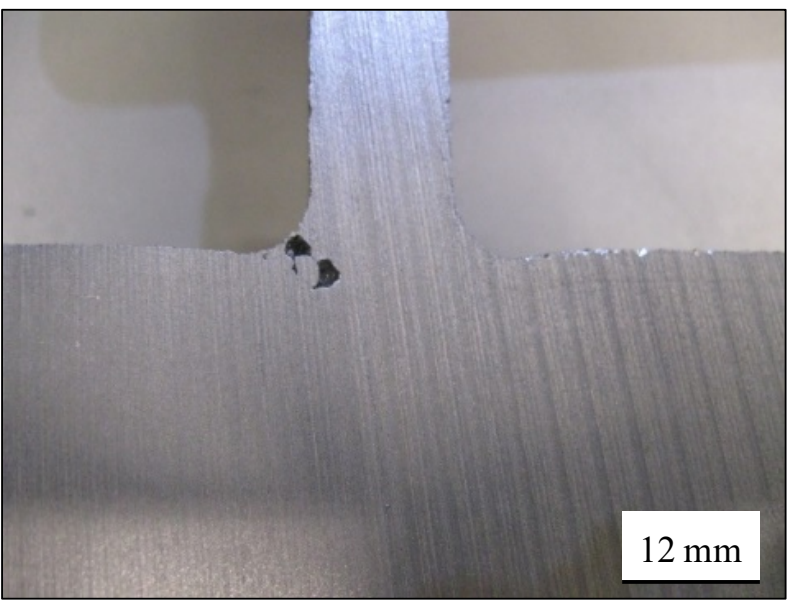

(b)
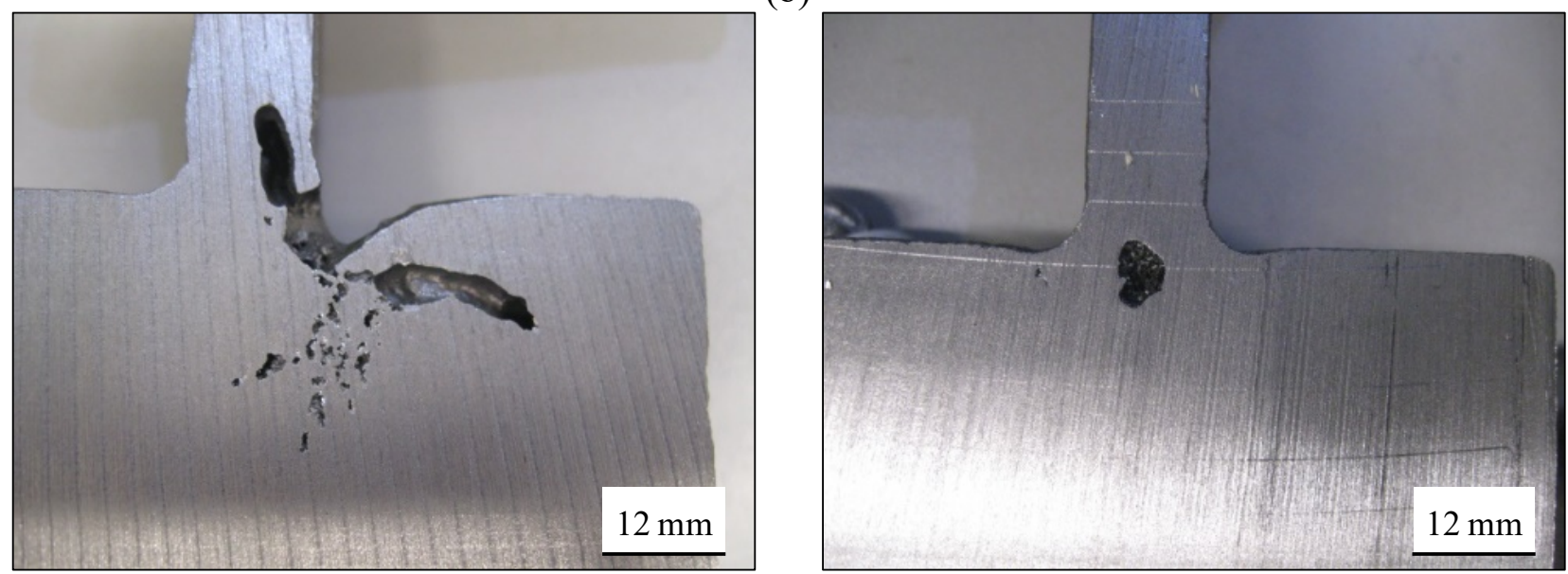

(c)

Figure 5. Shrinkage porosity found in test parts at different inoculation percentages: (a) $0.10 \%$, (b) $0.20 \%$ and (c) $0.30 \%$. Left column corresponds to alloy \#11 (hypoeutectic) and right column to alloy \#24 (eutectic).

Fig. 5 illustrates the combined effect of inoculation and carbon equivalent by comparing two alloys of series 2, alloys \#11 (hypoeutectic) and \#24 (eutectic). It is clearly seen that hypoeutectic composition leads to much higher shrinkage and that higher inoculation level increases it as well.

In previous studies, the relation between shrinkage and inoculation was looked for by using the minimum eutectic temperature $\mathrm{Te}_{\min }$ as a characteristic of inoculation efficiency. As can be inferred from Fig. 2, this relation may not be as simple as generally stated when considering together alloys with carbon equivalent varying from the hypo- to the hypereutectic range. For discussing this while using results from both series, the shrinkage values have been normalized by dividing by $35 \mathrm{~mm}^{3}$ 
the values of $\mathrm{V}_{\text {shr-riser }}$ and by $250 \mathrm{~mm}^{2}$ the values of $\mathrm{A}_{\text {shr-part }}$ Fig. 6 shows the evolution of normalized shrinkage with $\mathrm{Te}_{\min }$ for the two series, limited to alloys inoculated at $0.1 \mathrm{wt} . \%$ for series 2 as it was seen that other inoculation levels gave similar trends. In this figure, hypoeutectic, eutectic and hyper-eutectic alloys of both series have been represented with different symbols. Note that following the comments in relation with Fig. 4, it has been considered that hypoeutectic alloys have carbon equivalent lower than $4.39 \mathrm{wt} . \%$ for series 1 and lower than $4.30 \mathrm{wt} . \%$ for series 2 . Similarly, hypereutectic alloys have carbon equivalent higher than $4.42 \mathrm{wt} . \%$ for series 1 and higher than 4.36 wt. $\%$ for series 2 .

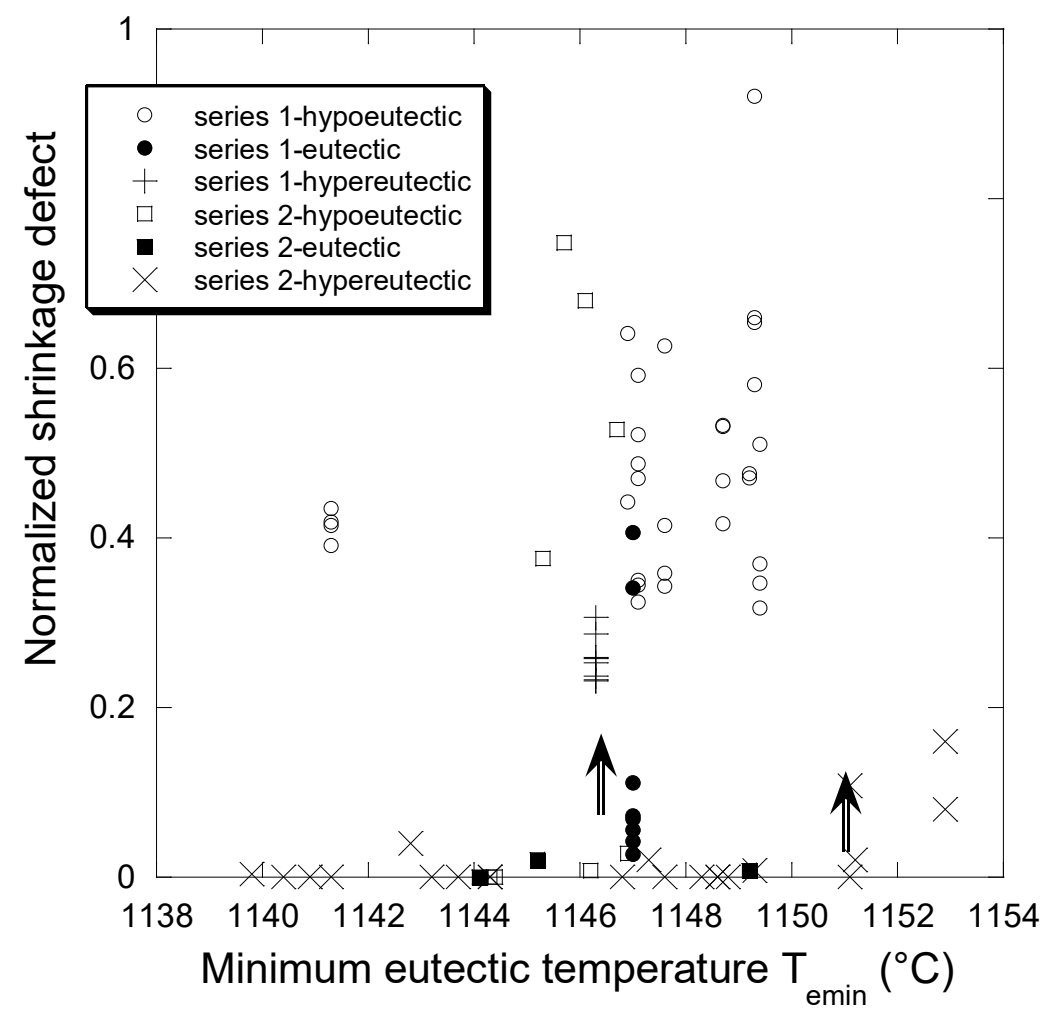

Figure 6. Evolution of normalized shrinkage with $\mathrm{Te}_{\min }$. The arrows indicate the value of $\mathrm{Te}_{\mathrm{min}}$ above which hypereutectic alloys present shrinkage, arrow to the left (resp. to the right) for alloys of series 1 (resp. of series 2).

It is clearly seen in Fig. 6 that a great majority of hypoeutectic alloys present shrinkage while only some of the eutectic alloys do so. The most interesting point is that the majority of hypereutectic alloys do not present shrinkage, except those with the highest values of $\mathrm{Te}_{\min }$. The $\mathrm{Te}_{\min }$ value above which shrinkage appears has been indicated with double arrows in Fig. 6, it is at $1146.5^{\circ} \mathrm{C}$ for series 1 (arrow to the left) and $1151.0^{\circ} \mathrm{C}$ for series 2 (arrow to the right). This difference in temperature between the two series of alloys may be partly related to the difference in the composition of the alloys and partly to inoculation efficiency in the two series.

As the value of $\mathrm{Te}_{\min }$ is expected to relate to primary formation of graphite (as discussed in relation with Fig. 2), the lower is the inoculation the lower would be the risk of shrinkage formation. This conclusion is not contradictory with previous reports showing the beneficial effect of inoculation in decreasing shrinkage $[4,8]$ as it should be pointed out that these earlier works compared inoculated to non-inoculated alloys. The present results show that inoculation is expected to decrease shrinkage tendency whereas over-inoculation appears to be detrimental.

\section{Discussion}

As shrinkage porosity seems to result from overall contraction of cast irons during solidification, it would be worthy for foundries to use hypereutectic alloys in which graphite precipitation is favoured with associated expansion to counteract contraction. As a matter of fact, hypereutectic cast 
irons are commonly employed with however some limitations in case of heavy-section castings where some graphite flotation should be avoided. The results obtained in the present work show an optimal composition for minimising shrinkage that corresponds to slightly hypereutectic alloys.

These slightly hypereutectic alloys show a solidification that occurs as a fully eutectic reaction, i.e. without any pre-eutectic solid deposition appearing on the thermal analysis curve. As carbon equivalent is decreased, there is a gradual increase of austenite precipitation which leads to a high contraction effect from the start of solidification and comparatively large porosity is observed. Such massive austenite nucleation and growth can be easily detected in cooling curves as this is associated to a well-defined liquidus arrest (as seen in Fig. 2). Similarly, hypereutectic alloys show a pre-eutectic reaction when the carbon equivalent becomes high enough. This arrest has been assigned to the formation and growth of austenite halos around previously formed graphite nodules [7] which seems to be the reason for the moderate increase of shrinkage porosity observed for hypereutectic alloys.

Regordosa and Llorca-Isern [4] reported that shrinkage porosity obtained in hypoeutectic and hypereutectic inoculated alloys differs in extent and characteristics. Pipe (open macroshrinkage), caved surfaces and internal macroshrinkage were detected in case of hypoeutectic alloys while only internal macroshrinkage with smaller size was present in hypereutectic alloys. Interestingly, the internal surfaces of macroshrinkage showed rounded dendrites with graphite layer on or graphite nodules in hypoeutectic alloys while smooth internal surfaces covered with an irregular graphite layer were found in hypereutectic alloys.

The beneficial effect of inoculation in decreasing shrinkage in cast irons has been consistently reported $[1,2,9,10]$. It has been also stated that effective inoculation would be that which enhances graphite nucleation and growth at the end of solidification [11]. However, an optimal inoculation level at around $0.10 \mathrm{wt} \% \%$ has been evidenced in the present study, see Figs. 4 and 5. Although the reason for such a behaviour is not fully clear, it is related to solidification proceeding in one single eutectic reaction. For hypereutectic alloys, the optimal range of inoculant addition is such that there is no pre-eutectic reaction which would lead to early austenite formation that could hinder liquid feeding at the end of solidification. This idea is supported by the fact that hypereutectic alloys with the largest shrinkage porosity are those with the highest $\mathrm{Te}_{\min }$ values (Fig. 6).

As it has been mentioned previously, $\mathrm{Te}_{\min }$ has been reported to increase as graphite formation is favoured during solidification [8]. The present results lead to reconsider some existing criterion used in foundry practice which considers that maximisation of $\mathrm{Te}_{\min }$ is necessary to avoid shrinkage formation in castings.

The influence of silicon and magnesium contents on shrinkage size has been also evaluated for the two series of alloys. In the first case, silicon effect has been considered as part of carbon equivalent as the variation of this element is strongly related to carbon contents. In case of magnesium content, any valuable correlation has not been found. This fact could be due to the strong influence of carbon equivalent and inoculation on shrinkage incidence in the present work. The specific effect of silicon and magnesium will be the subject of future investigations.

\section{Conclusions}

For evaluating shrinkage formation, two different castings have been considered in the present work which were produced using different experimental conditions, compositions and inoculation levels. In both series, the highest shrinkage tendency was observed for hypoeutectic compositions while a minimum shrinkage appeared for slightly hypereutectic compositions. From that minimum, an increase of the shrinkage tendency was observed for hypereutectic compositions.

While inoculation is known to decrease shrinkage defects, the present results showed an optimal inoculation level at $0.1 \%$ of the casting weight. An increase of the inoculant addition above this level promoted shrinkage, especially for hypereutectic alloys. Furthermore, hypereutectic alloys presenting shrinkage are those showing the highest $\mathrm{Te}_{\min }$ values as a result of increased graphite nucleation and growth. As a consequence, it may be claimed that higher $\mathrm{Te}_{\min }$ values are not always beneficial for avoiding shrinkage formation in castings. 


\section{Acknowledgements}

Part of this work has been supported by the Centro para el Desarrollo Tecnológico Industrial (CDTI) of the Spanish Government (Ref. IDI-20150535). The authors would also like to thank AGAUR for awarding the scholarship for the Industrial Doctorate promoted by the Catalan Government.

\section{References}

[1] T. Skaland, A new approach to ductile iron inoculation, AFS Trans., vol 109 (2001) 1073-1084.

[2] P. Larrañaga, J. Sertucha, R. Suárez, Análisis del proceso de solidificación en fundiciones grafíticas esferoidales, Rev. Metal., vol 42 (2006) 244-255. In Spanish, abstract in English.

[3] J. M. Gutiérrez, A. Natxiondo, J. Nieves, A. Zabala, J. Sertucha, Statistical study to evaluate the effect of processing variables on shrinkage incidence during solidification of nodular cast irons, Metall. Mater. Trans. A, vol 48A (2017) 1827-1840. DOI: 10.1007/s11661-017-3969-1.

[4] A. Regordosa, N. Llorca-Isern, Microscopic characterization of different shrinkage defects in ductile irons and their relation with composition and inoculation process, Int. J. Metal. (2016) online version. DOI: 10.1007/s40962-016-0120-9.

[5] K. Soivio, L. Elmquist, Influence of inoculation on shrinkage defects in spheroidal graphite cast iron, Int. J. Cast Metal Res., vol 26 (2013) 220-227. DOI: 10.1179/1743133613Y.0000000057.

[6] M. Castro, M. Herrera, M. M. Cisneros, G. Lesoult, J. Lacaze, Simulation of thermal analysis applied to the description of hypereutectic SG irons, Int. J. Cast Metals Res., vol 11 (1999) 369374. DOI: http://dx.doi.org/10.1080/13640461.1999.11819301.

[7] M. D. Chaudhari, R. W. Heine, C. R. Loper, Principles involved in the use of cooling curves in ductile iron process control, AFS Trans., vol 82 (1974) 431-440.

[8] P. Larrañaga, J. M. Gutiérrez, A. Loizaga, J. Sertucha, R. Suárez, A computer-aided system for melt quality and shrinkage propensity evaluation based on the solidification process of ductile iron, AFS Trans., vol 116 (2008) 547-561.

[9] D. White, Avoiding shrinkage defects and maximizing yield in ductile iron, AFS Trans., vol 120 (2012) paper 12-081.

[10] A. Tadesse, H. Fredriksson, The effect of inoculation on the thermal expansion/contraction during solidification of gray cast iron, Mater. Sci. Forum, vol 790-791 (2014) 447-451. DOI: 10.4028/www.scientific.net/MSF.790-791.447.

[11] T. Skaland, Ductile iron shrinkage control through graphite nucleation and growth, Int. J. Cast Met. Res., vol 16 (2003) 11-16. DOI: 10.1179/136404603225006611. 